\title{
Historical analysis of environmental conditions during Florida Red Tide
}

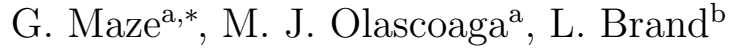 \\ ${ }^{a}$ Department of Ocean Sciences, Rosenstiel School of Marine and Atmospheric Science, \\ University of Miami, Miami, Florida, USA. \\ ${ }^{b}$ Department of Marine Biology and Ecology, Rosenstiel School of Marine and \\ Atmospheric Science, University of Miami, Miami, Florida, USA.
}

\section{Abstract}

The most frequent and intense harmful algal blooms, of the toxic dinoflagellate Karenia brevis, occur on the West Florida Shelf. Many aspects relating to such blooms remain poorly known, including environmental conditions during their occurrence. Here the position of the Loop Current, river runoff, and along- and cross-shore winds are analyzed, isolating persistent periods of no bloom (less than 100 cell L ${ }^{-1}$ ) and large blooms (more than $10^{5}$ cell $\mathrm{L}^{-1}$ ). From 1993 to 2007, 9 instances are detected with a large bloom and 37 instances are found with no bloom. A two-sample unequal variance T-Test analysis reveals that the difference between periods of large blooms and periods with no bloom are statistically significant to the $90 \%$ confidence level for the Loop Current's position. Periods of large blooms are found to occur only when the Loop Current is in its northern position, due to the enhanced retention on the shelf.

Keywords: Karenia brevis, Loop Current, West Florida Shelf

\footnotetext{
${ }^{*}$ Corresponding author.

Email addresses: gmaze@rsmas.miami.edu (G. Maze), jolascoaga@rsmas.miami.edu (M. J. Olascoaga), lbrand@rsmas.miami.edu (L. Brand) 


\section{Introduction}

Along the West Florida Shelf (WFS) in the Gulf of Mexico (GoM) a common species of Harmful Algal Blooms (HAB) is Karenia brevis, otherwise known as Florida Red Tide. This dinoflagellate produces brevetoxins, a suite of polyether neurotoxins, which are hazardous to marine life, as well as to humans from consumption of contaminated fish or shellfish that leads to neurotoxic shellfish poisoning (Watkins et al., 2008), and from breathing of brevotoxin contaminated air that leads to respiratory distress (Fleming et al., 2005).

Despite many decades of research, when or where blooms of $K$. brevis will occur can still not be predicted. No environmental factor has been found to be a strong predictor of $K$. brevis. This species reproduces slowly, only around 0.3 divisions per day (Magana and Villareal, 2006). A bloom can only develop if the physical dispersal of the water is less than the growth rate, as recognized by Kierstead and Slobodkin (1953) and Slobodkin (1953). Many $\mathrm{HAB}$ occur in bays and estuaries, where dispersal is reduced by confinement and estuarine circulation patterns; however K. brevis forms blooms primarily over the continental shelf, where advection and dispersal can be relatively strong. But drifter trajectory data (Yang et al., 1999) and Lagrangian analysis of the circulation on the WFS (Olascoaga et al., 2006) reveal the presence of a persistent cross-shelf transport barrier that prevents mixing of WFS and GoM waters. It is hypothesized that times and locations of reduced mixing over the continental shelf will be conducive to bloom development.

The Loop Current (LC) is the most important feature in the circulation 
of the GoM. It is well known that the LC has a cyclical northward/southward excursion (Sturges and Evans, 1983). In its southernmost position, the LC enters the GoM through the Yucatan Straits and flows to the northeast exiting through the Florida Straits, as shown in the sea surface height (SSH) field in Figure 1b. In the northern most position the LC will flow north from the Yucatan Straits into the northern GoM and then return to flow south and exit the GoM, as shown in the SSH field in Figure 1a. Once in its northernmost position, it will form and shed a large anticyclonic eddy which propagates westward in the GoM (Forristall and Cooper, 1992). The northward/southward excursion of the LC is variable, with the average period being around 1 cycle every 8 to 18 months (Sturges and Evans, 1983). The position of the LC has been shown to influence the circulation on the WFS (Hetland et al., 1999), enhancing the retention rate in the coastal area, possibly when it is in a northern position (Olascoaga, 2010). Few studies have focused on the importance of LC position on the persistence (Olascoaga, 2010) or lack of a bloom (Weisberg et al., 2014).

In the area covered for this study the main rivers of concern are the Caloosahatchee River, which drains the main watershed from Lake Okeechobee, and the Peace River. Other rivers in the area include the Hillsborough River, the Alafia River, the Little Manatee River, and the Manatee River, which form the Tampa Bay River System. While the other rivers in this area are natural rivers, the Caloosahatchee River has several locks to regulate the water level of the lake. Rivers are not only a source of freshwater but also a source of nutrients. GoM waters are commonly considered oligotrophic with background concentrations of inorganic nitrogen ranging 
from $0.02 \mu \mathrm{M}$ to $0.2 \mu \mathrm{M}$ and inorganic phosphorus ranging from $0.025 \mu \mathrm{M}$ to $0.24 \mu \mathrm{M}$, which are not enough to support a persistent bloom (Odum et al., 1955; Vargo et al., 2008). Along with the very important influx of nutrients, the rivers also supply freshwater which can create a highly stratified water column. This type of environment can create conditions ideal for dinoflagellates like $K$. brevis, or cyanobacteria to out-compete the faster growing plankton, like diatoms (Erdner et al., 2008; Chorus and Bartram, 1999; Smayda, 1997).

For the generation of a large bloom biomass, a large amount of nutrients are needed. Many hypotheses have been proposed, but there is no agreement at the present time on the major sources of nutrients that may be stimulating the initiation of a bloom or sustaining it over time. Early research (Ketchum and Keen, 1948; Odum et al., 1955; Ingle and DeSylva, 1955) focused on the rivers along the west coast of Florida as being a major source of nutrients for blooms of K. brevis. More recently, Dixon and Steidinger (2004), Brand and Compton (2007), and Yentsch et al. (2008) have also suggested land runoff as a major source of nutrients. It is hypothesized that blooms occur at times of greater river flow.

Winds along the WFS play a large role in the seasonal circulation. The winds in the late fall and winter are usually from the northeast and are upwelling favorable, while summer winds are from the south or southeast and downwelling favorable (Weisberg et al., 2001; Liu and Weisberg, 2012). Many of the past works have postulated upwelling favorable winds will provide an increase of nutrients leading to a bloom (Tester and Steidinger, 1997; Stumpf et al., 2008). 


\section{Data and Methods}

To investigate the influence of these environmental factors on the Florida Red Tide, the difference of each during the occurrence of periods of intense blooms and periods of no bloom from historical records were examined. Because periods of already intense blooms are looked at, the mechanisms examined in this paper are studying the maintenance of a bloom and not the initiation.

The federal Ecology and Oceanography of Harmful Algal Blooms (ECOHAB) and Florida Fish Wildlife Conservation Commission along with several other programs, have created a national database of $K$. brevis blooms. This database contains bloom information from as far back as 1954. Most of the data were logged in response to a bloom that was seen, although some of the data are from 2 to 5 year studies that involved regular monitoring. Due to the non-regularity of the measurements, the data are skewed with most measurements taken at times of large blooms and few measurements taken at background concentrations. This skewness prevents using some traditional statistical analyses on $K$. brevis concentrations themselves. Rather than using the actual concentration values, using the time periods with high and low concentrations to analyze the difference of other time series with normal distributions, allows statistical analysis of the difference between the two.

The $K$. brevis data were restricted to measurements taken from $26.5^{\circ} \mathrm{N}$ to $28^{\circ} \mathrm{N}$ and $85^{\circ} \mathrm{W}$ to coast (red box in Figure 1a). For days with multiple observations within this region the maximum value was used. Periods when

the $K$. brevis concentration remains above $10^{5}$ cell $\mathrm{L}^{-1}$ for a minimum of 10 consecutive days, with no gaps in this concentration lasting more than 5 
consecutive days or totaling $20 \%$ of the length of the bloom are designated as large blooms. At concentrations above $10^{5}$ cell $\mathrm{L}^{-1}, K$. brevis are visible to the naked eye and are at toxic levels, and for the purpose of this research are considered a large bloom. Periods when the $K$. brevis concentration remains below 100 cell $\mathrm{L}^{-1}$ for a minimum of 10 consecutive days, with no gaps in this concentration lasting more than 5 consecutive days or totaling $20 \%$ of the length of the bloom are designated as no blooms. To test the sensitivity of the criteria used to define a large bloom or no bloom period, the analysis was repeated using 5, 8, 12, and 15 day lengths of blooms with $20 \%$ gaps in time period for each and showed similar trends (not shown here). Periods that span seasons were split to look at the difference between seasons using the solstice and equinox dates.

The LC can be identified from altimetry data as an area with SSH higher than the surrounding waters. Analysis of altimetry data from AVISO (Archiving, Validation and Interpretation of Satellite Oceanographic data) over the period 1993 to 2007 has shown the LC typically has an SSH of $177 \pm$ $15.0 \mathrm{~cm}$ while common waters have a $\mathrm{SSH}$ of $145 \pm 5.1 \mathrm{~cm}$ (Lindo-Atichatia et al., 2013). The difference between the maximum altimetric SSH along two segments of the $300 \mathrm{~m}$ isobath, one centered at $26.5^{\circ} \mathrm{N}$ and the other at $24.5^{\circ} \mathrm{N}$, was used as a proxy for the LC position (Figure $1 \mathrm{~b}$ ). When the LC is in its northern position (Figure 1a) the SSH is larger near the northern 300 $\mathrm{m}$ isobath segment, which gives a positive SSH difference. The LC pressure over the WFS edge results in a southward jet along the shelf break, leaving a weak circulation over the rest of the shelf. When the LC is in the southern position (Figure 1b) the SSH difference is negative. When the LC interac- 
tion with the WFS is in its southern part the southward flow penetrates on the shelf, affecting the circulation all the way to the coast (Hetland et al., 1999).

Data on the outflow of rivers along the WFS were gathered from the United States Geological Survey (USGS) National Water Information System and the South Florida Water Management District (SWFMD). Data for the Peace River (at Arcadia) were collected from 1931 through 2010 from USGS. The Caloosahatchee River contains a system of locks, and the data for these locks were collected from 1971 through 2009 from SFWMD. The river data were measured daily and recorded in cubic feet per second (CFS). Data for the Tampa Bay rivers were also examined, but their overall flows are much smaller and showed no significance and are not shown here.

Wind data were gathered from the National Buoy Data Center (NBDC) via the NOAA website. The buoy located in Venice was selected due to the location, the length of data available, and minimal gaps in the data set. The time series examined contains hourly wind speeds and wind directions from January 1993 through December 2009. To determine upwelling and downwelling favorable winds, the data were separated into along- and crossshore winds using a $23^{\circ}$ shift from an $\mathrm{x}-\mathrm{y}$ axis. These data were filtered to remove the daily and hourly oscillations.

For each of the above data sets, averages and standard deviations were calculated for each large bloom and no bloom period identified. The individual averages and standard deviations for these periods were then used to calculate the total mean and standard deviations for bloom and no bloom periods. The degrees of freedom were calculated for each term by 


$$
\text { df }:=\frac{\left(s_{B}^{2} / n_{B}+s_{N B}^{2} / n_{N B}\right)^{2}}{\left.\left(s_{B}^{2} / n_{B}\right)^{2} /\left(n_{B}-1\right)+\left(s_{N B}^{2} / n_{N B}\right)^{2} /\left(n_{N B}-1\right)\right)},
$$

where $s_{B}\left(s_{N B}\right)$ is the overall standard deviation for the time series during blooms (no blooms) with $n_{B}\left(n_{N B}\right)$ elements. The overall standard deviation for bloom (no bloom) periods, $s_{B}\left(s_{N B}\right)$, were calculated by

$$
\operatorname{std}:=\sqrt{\left(s_{1}^{2}+s_{2}^{2}+\ldots+s_{n}^{2}\right) / n}
$$

where $s_{1} \ldots s_{n}$ are the individual standard deviations for bloom (no bloom) periods, and $n$ is $n_{B}\left(n_{N B}\right)$. A unequal variance T-test (Welch, 1947) was calculated by

$$
t:=\frac{\bar{X}_{B}-\bar{X}_{N B}}{s_{\left(\bar{X}_{B}-\bar{X}_{N B}\right)}}
$$

where $\bar{X}_{B}$ is the total mean during bloom periods, $\bar{X}_{N B}$ is the total mean during no bloom periods and

$$
s_{\left(\bar{X}_{B}-\bar{X}_{N B}\right)}:=\sqrt{s_{B}^{2} / n_{B}+s_{N B}^{2} / n_{N B}} .
$$

The results were tested using an $\alpha$ level of 0.10 .

Because the original observations of $K$. brevis concentrations are skewed, only the time periods associated with $K$. brevis high and low concentrations, not the actual concentrations, are used to eliminate the bias. The population distributions of the examined data sets within these periods are near normal and therefore a T-test is an appropriate method.

For the SSH difference, the null hypothesis $\left(H_{o}\right)$, that there is no difference between periods of bloom and no bloom, was tested against the alternative hypothesis $\left(H_{a}\right)$, that the $\mathrm{SSH}$ difference is larger during times of bloom than no bloom. For the Peace River and Caloosahatchee River outflow for 
all periods, the null hypothesis, that there is no difference in the river outflow between periods of bloom and no bloom, was tested against the alternative hypothesis, that the river outflow is larger during times of bloom than no bloom. For along- and cross- shore winds, the null hypothesis, that there is no difference between the winds during time of bloom and no bloom, was tested against the alternative hypothesis, that there is a difference in the winds during periods of bloom and no bloom (Table 1).

Next, the no bloom periods with positive SSH were examined by winterspring and summer-fall with the bloom periods in the corresponding seasons. For the Peace River and Caloosahatchee River in summer-fall months, the null hypothesis, that there is no difference in river outflow between periods of bloom and no bloom, was tested against the alternative hypothesis, that the river outflow is larger in the periods of bloom than no bloom. For the Peace River and Caloosahatchee River outflow in summer-fall months, the null hypothesis, that there is no difference in river outflow between period of bloom and no bloom, was tested against the alternative hypothesis, that the river outflow is lower during times of bloom than no bloom. For winterspring and summer-fall along- and cross- shore winds, the null hypothesis, that there is no difference in the winds during times of bloom and no bloom, was tested against the alternative hypothesis, that there is a difference in the winds between periods of bloom and no bloom (Table 2). Using the degrees of freedom a corresponding probability of the two averages coming from the same population, the $p$ value, was calculated for each of the data sets using a $\mathrm{T}$ distribution table. 


\section{Results}

From 1954 to 2009, 13 instances were detected with a large bloom and 80 instances were found with no bloom detected. Of the 13 blooms detected, 5 spanned seasons. Separating the latter seasonally, a total of 18 blooms were counted. Six blooms occurred in the summer months, 4 blooms occurred in the fall months (3 of which were continuation of a summer bloom), 5 in the winter months, and 3 in the spring months (two of which were a continuation of a winter bloom). Thus while blooms of any intensity tend to be more common during late summer and fall months (Brand and Compton, 2007), strong bloom occurrences are quite uniformly spread over the seasons. Of the 80 no bloom periods detected, 23 spanned seasons. Discriminating these seasonally, a total of 103 no bloom periods were counted. Nineteen no blooms occurred in the summer months, 22 occurred in the fall months, 31 occurred in the winter months, and 31 occurred in the spring months.

For the remainder of the results presented, only the periods from 1993 to 2007 are considered due to the availability of satellite altimetry data. For this period 9 instances were detected with a large bloom and 37 instances were found with no bloom detected. Of the 9 blooms detected, 4 spanned seasons. Separating the latter seasonally, a total of 13 blooms were counted. Four blooms occurred in the summer months, 3 blooms occurred in the fall months (all were continuation of a summer bloom), 4 in the winter months, and 2 in the spring months (one was a continuation of a winter bloom). Of the 37 no bloom periods detected, 10 spanned seasons. Discriminating these seasonally, a total of 47 no bloom periods were counted. Nine no blooms occurred in the summer months, 10 occurred in the fall months, 13 occurred 
in the winter months, and 15 occurred in the spring months.

Figure 2 shows a series of bar charts for the various environmental variables considered here during bloom (left) and no bloom (right) periods. More specifically, for each bloom and no bloom period identified (horizontal axis), the mean value and standard deviation of each environmental variable is depicted (vertical axis). From the inspection of the SSH bar charts (top), it is clear that bloom periods always have the $\mathrm{LC}$ in a northern position ( $\mathrm{SSH}$ difference is positive). This is consistent with the expected high retention on the WFS favored by a LC in a northern position (Olascoaga, 2010). During no bloom periods the LC can be in its either northern or southern position. About $30 \%$ of the no bloom periods found have a negative SSH difference, which indicates a southern LC position. From the inspection of the bar charts for river discharge (middle) and wind intensity (bottom), it is not possible to identify any clear pattern that enables a differentiation between bloom and no bloom periods.

The two-sample unequal variance T-test analysis reveals that the difference between periods of large blooms and periods with no bloom are statistically significant to the $90 \%$ confidence level (with $p<.1$ ) for LC position, and the Peace and Caloosahatchee River discharge (Table 1). This means that the null hypothesis can be rejected in favor of the alternative hypothesis, pointing to a difference between periods of large bloom and periods of no bloom. The alongshore and offshore winds show no statistically significant difference between periods of bloom and no bloom.

While the $p$-value was significant for river discharges, this is not evident from the inspection of the bar charts in Figure 2 or the matrices in Table 3. 
The second and third matrices in Table 3 respectively show the counts for below average and above average river outflow of the Caloosahatchee River and Peace River. For the no bloom periods, only the periods with a northern $\mathrm{LC}$ are considered. The rationale for this is that including all the data when the LC is in its southern position obscures the analysis. More specifically, the LC in a southern position will prevent a bloom from developing in presence of other environmental conditions favoring bloom development. Of the 31 no blooms with the LC in the northern position, 18 have a Caloosahatchee River discharge less than average and 25 have a Peace River discharge less than average (Table 3). It should be noted that K. brevis blooms not only require high retention rates, but also an adequate amount of nutrients to support a bloom.

From the inspection of Figure 2 it is clear that freshwater discharge during bloom periods varies considerably across seasons. This suggests that analyses discriminated by seasons are required. Therefore, two separate periods, summer-fall and winter-spring, are considered and carry a sequential analysis of the time series in such periods is conducted. As a first step, all the no bloom periods when the LC is in a southern position (16 of the 47 no blooms) are ignored, and compare again bloom and no bloom periods for the other environmental factors for each seasonal group. Next any outliers within these seasonal groups are examined, specifically winter-spring 1998 which has an unusually large river outflow, capable of skewing the results.

The T-test analysis (Table 2) reveals that the difference between periods of large blooms and periods with no bloom are statistically significant with $p<0.1$ for Peace and Caloosahatchee River discharge during summer-fall, 
which means the null hypothesis can be rejected and the alternative hypothesis can be accepted. During summer and fall, periods of large blooms have greater river outflow than periods with no bloom. While during winter and spring, periods of large blooms typically have lower river outflow than periods with no bloom. A surplus of nutrients will not prevent a K. brevis bloom, however it can favor the growth of other species of plankton. A well stratified water column, such as what is found in summer and fall months, favors slower growing plankton, like $K$. brevis. A well-mixed water column, such as what is found in winter and spring months, can favor faster growing plankton, like diatoms, given a large supply of nutrients.

The T-test analysis reveals that the difference between periods of large blooms and periods with no bloom are statistically significant with $p<0.1$ for the cross-shore wind intensity during winter-spring (Table 2). Which means the null hypothesis can be rejected and the alternative hypothesis can be rejected.

Further insight can be gained by the inspection of the probability distribution functions (PDFs) of river discharge (Figure 3, top rows) and wind intensity (Figure 3, bottom rows) during bloom (black) and no bloom (grey) conditions in summer-fall (left) and winter-spring (right). Consistent with the T-test analysis, these PDFs reveal that during summer-fall no-bloom periods have smaller river discharge than bloom periods. While bloom and nobloom periods results are statistically different for wind intensity according to T-test analysis only during winter-spring in the cross-shore direction, the PDFs reveal that no-bloom periods appear to have more intense cross-shore winds than bloom periods. Also, in summer-fall upwelling favorable winds 
appear to prevail during bloom periods, while downwelling favorable winds prevail during no-bloom periods. (Note, however, that the T-test analysis is not statistically significant for the along coast wind.)

\section{Discussion and Summary}

Karenia brevis is a slow growing dinoflagellate, capable of a growth rate of only approximately 0.3 divisions per day (Magana and Villareal, 2006), which requires an area with a high retention rate (mixing slower than growth rate) to form a bloom. A Lagrangian analysis of the circulation on the WFS shows a persistent cross-shelf transport barrier that prevents mixing of shelf and GoM waters (Olascoaga et al., 2006; Olascoaga, 2010), enhancing the retention rate toward the coast. This analysis suggests that when the LC is in its northern position the retention rate in the coastal area increases, allowing a bloom to form given that other conditions are ideal. Conversely when the $\mathrm{LC}$ is in a southern position, the high retention rates required for a bloom are reduced. Even if all of the other conditions are ideal for forming a bloom, if the LC is in a southern position the K. brevis cells will not stay in the area long enough to grow into a bloom.

The findings presented here about the importance of the $\mathrm{LC}$ in the maintenance of a bloom are not inconsistent with the findings of Weisberg et al. (2014), who found that when the LC is in a southern position a bloom will not form, however the reasonings are different. Weisberg et al. (2014) propose that a $\mathrm{LC}$ is the southern position promotes prolonged interaction with the 300-m isobath creating upwelling of deep nutrients, which will allow a diatom bloom to outcompete any possible $K$. brevis bloom. 
In summary the analysis of historical environmental data for periods of large $K$. brevis blooms compared to periods of no bloom indicates the importance of the position of the LC in bloom maintenance. As hypothesized, periods of large blooms are found to occur only when the LC is in its northern position (Table 3). It appears that, the LC northern position is necessary but not sufficient to allow the occurrence of a bloom. There must be another combination of physical and biological factors that has not yet been identified and will require further study, however this research does support the idea that river outflow and winds may play an as yet undefined role. It is important to note there cannot be a prolonged large bloom when the $\mathrm{LC}$ is in a southern position, which is the first definitive predictor of bloom possibility shown for the time period examined.

\section{Acknowledgments}

Thank you Alyson Tockstein for proof reading of the manuscript. Support for this work was provided by the Oceans and Human Health Center at the University of Miami Rosenstiel School under the NSF Grants OCE 1127813. Partial support was also provided by the Gulf of Mexico Research

Initiative through the Consortium for Advanced Research on Transport of Hydrocarbon in the Environment (CARTHE) at the University of Miami Rosenstiel School of Marine and Atmospheric Science.

\section{References}

Brand, L. E., Compton, A., 2007. Long-term increase of Karenia brevis abundance along the Southwest Florida Coast. Harmful Algae 6, 232-252. 
Chorus, I., Bartram, J., 1999. Toxic cyanobacteria in water: A guide to their public health consequences, monitoring and management.

Dixon, L. K., Steidinger, K. A., 2004. Correlation of Karenia brevis presence in the eastern Gulf of Mexico and with rainfall and riverine flow. In: Steidinger, K. A., Landberg, J. H., Tomas, C. R., Vargo, G. A. (Eds.), Harmful Algae 2002. UNESCO, pp. 29-31.

Erdner, D., Dyble, J., Parsons, M., Stevens, R., Hubbard, K., Wrabel, M., Moore, S., Lefebvre, K., Anderson, D., Bienfang, P., Bidigare, R., Parker, M., Moeller, P., Brand, L. E., Trainer, V., 2008. Centers for oceans and human health: a unified approach to the challenge of harmful algal blooms. Environ Health 7, S2.

Fleming, L. E., Kirkpatrick, B., Backer, L. C., Bean, J. A., Wanner, A., Dalpra, D., Tamer, R., Zaias, J., Cheng, Y. S., Pierce, R., Naar, J., Abraham, W., Clark, R., Zhou, Y., Henry, M. S., Johnson, D., Van De Bogart, G., Bossart, G. D., Harrington, M., Baden, D. G., 2005. Initial evaluation of the effects of aerosolized Florida red tide toxins (brevetoxins) in persons with asthma. Environ Health Perspect 113, 650-657.

Forristall, G. Z., K. J. S., Cooper, C. K., 1992. Evolution and kinematics of a Loop Current eddy in the Gulf of Mexico during 1985. J. Geophys. Res. $97,2173-2184$.

Hetland, R. D., Ya Hsueh, R. R. L., Niiler, P., 1999. A loop current-induced jet along the edge of the West Florida Shelf. Geophys. Res. Lett. 26, 22392242. 
Ingle, R., DeSylva, D., 1955. The red tide. Fl. State Bd. Conserv. Educ. Ser. $1,1-30$.

Ketchum, B. H., Keen, J., 1948. Unusual phosphorus concentration in the Florida "red tide" sea water. J. Mar. Res. 7, 17-21.

Kierstead, H., Slobodkin, L., 1953. The size of water masses containing plankton blooms. J. Mar. Res. 12, 141-147.

Lindo-Atichatia, D., Bringas, F., Goni, G., 2013. Loop Current excurisions and ring detachments during 1993-2009. International Journal of Remote Sensing 34, 5042-5053.

Liu, Y., Weisberg, R., 2012. Seasonal variability on the West Florida Shelf. Prog. Oceanog. 104.

Magana, H., Villareal, T., 2006. The effect of environmental factors on the growth rate of Karenia brevis (Davis) G. Hansen and Moestrup. Harmful Algae 5 (2), 192-198.

Odum, H., Lackey, J., Hynes, J., Marshall, N., 1955. Some red tide characteristics during 1952-1954. Bull.Mar. Sci. Gulf Carrib. 5, 247-258.

Olascoaga, M., 2010. Isolation on the West Florida Shelf with implications for red tides and pollutant dispersal in the Gulf of Mexico. Nonlin. Proc. Geophys. 17, 685-696.

Olascoaga, M., Rypina, I., Brown, M. G., Beron-Vera, F. J., Koçak, H., Brand, L. E., Halliwell, G. R., Shay, L., 2006. Persistant transport barrier on the West Florida Shelf. Geophys. Res. Let. 33 (L22). 
Slobodkin, L., 1953. A possible initial condition for red tides on the coast of Florida. J. Mar. Res. 7, 145-155.

Smayda, T. J., 1997. Harmful algal blooms: Their ecophysiology and general relevance to phytoplankton blooms in the sea. Linmol. Oceanogr. 42 (5b), $1137-1153$.

Stumpf, R., Litaker, R., Lanerolle, L., Tester, P., 2008. Hydrodynamic accumulation of Karenia off the west coast of Florida. Cont. Shelf Res. 28, 189-213.

Sturges, W., Evans, C., 1983. On the Variability of the Loop Current in the Gulf of Mexico. J. Mar. Res. 41, 639-653.

Tester, P., Steidinger, K., 1997. Gymnodinium breve red tide blooms: Initiation, transport, and consequences of surface circulation. Linmol. Oceanogr. 42, 1039-1051.

Vargo, G., Heil, C., Fanning, K., Dixon, L. K., Neely, M., Ault, D., Murasko, S., Havens, J., Walsh, J., Bell, S., 2008. Nutrient availability in support of Karenia brevis blooms on the central West Florida Shelf: what keeps Karenia blooming. Cont. Shelf Res. 28, 73-98.

Watkins, S., Reich, A., Fleming, L., Hammond, R., 2008. Neurotoxic shellfish poisoning. Mar. Drugs 6.

Weisberg, R., Lil, Z., Muller-Karger, 2001. West Florida Shelf response to local wind forcing: April 1998. J. Geophys. Res. 26. 
Weisberg, R., Zheng, L., Lui, Y., Lembke, C., Lenes, J., Walsh, J., 2014. Why a Red Tide was not observed on the West Florida Continental Shelf in 2010. Harmful Algae 38, 119-126.

Welch, B., 1947. The generalization of Student's' problem when several different population variances are involved. Biometrika, 28-35.

Yang, H., Weisberg, R. H., Niiler, P., Sturges, W., Johnson, W., 1999. Lagrangian circulation and forbidden zone on the west florida shelf. Continental Shelf Research 19 (9), 1221 - 1245.

Yentsch, C., Lapointe, B., Poulton, N., Phinney, D., 2008. Anatomy of a red tide bloom off the southwest coast of Florida. Harmful Algae 7, 817-826. 


\begin{tabular}{l|c|c|c|c|c|c|c}
\hline Variable & Bloom & No bloom & $H_{o}$ & $H_{a}$ & T value & P value & df \\
\hline SSH difference & $9.66 \pm 7.80$ & $3.95 \pm 9.49$ & $X b=X n b$ & $X b>X n b$ & 2.13 & 0.020 & 23 \\
Cross shore wind $(\mathrm{m} / \mathrm{s})$ & $0.029 \pm 0.364$ & $0.180 \pm 0.826$ & $X b=X n b$ & $X b \neq X n b$ & 0.93 & 0.160 & 38 \\
Alongshore wind $(\mathrm{m} / \mathrm{s})$ & $-0.775 \pm 0.766$ & $-0.604 \pm 0.965$ & $X b=X n b$ & $X b \neq X n b$ & 0.66 & 0.259 & 27 \\
Peace River (CFS) & $1805.5 \pm 1666.1$ & $776.9 \pm 952.6$ & $X b=X n b$ & $X b>X n b$ & 2.04 & 0.030 & 13 \\
Caloosahatchee river (CFS) & $3787.8 \pm 3275.2$ & $2006.6 \pm 1921.1$ & $X b=X n b$ & $X b>X n b$ & 1.79 & 0.047 & 13 \\
\hline
\end{tabular}

Table 1: The blooms and no bloom averages, the null and alternative hypothesis, the $\mathrm{T}$ value and the $\mathrm{P}$ value for each data set. 


\begin{tabular}{|c|c|c|c|c|c|c|c|}
\hline Variable & Bloom & No bloom & $H_{o}$ & $H_{a}$ & $\mathrm{~T}$ value & $\mathrm{P}$ value & $\mathrm{df}$ \\
\hline Cross-shore wind $(\mathrm{m} / \mathrm{s})$ (summer-fall) & $0.051 \pm 0.341$ & $0.114 \pm 0.744$ & $X b=X n b$ & $X b \neq X n b$ & -0.23 & 0.826 & 12 \\
\hline Alongshore wind $(\mathrm{m} / \mathrm{s})$ (summer-fall) & $-0.593 \pm 0.755$ & $-0.097 \pm 0.757$ & $X b=X n b$ & $X b \neq X n b$ & -1.08 & 0.298 & 14 \\
\hline Cross-shore wind $(\mathrm{m} / \mathrm{s})$ (winter-spring) & $0.002 \pm 0.421$ & $0.445 \pm 0.634$ & $X b=X n b$ & $X b \neq X n b$ & -1.95 & 0.072 & 14 \\
\hline Alongshore wind $(\mathrm{m} / \mathrm{s})$ (winter & $-0.986 \pm 0.790$ & $-0.820 \pm 0.734$ & $X b=X n b$ & $X b \neq X n b$ & -0.46 & 0.660 & 9 \\
\hline Peace River (CFS) (summer-fall) & $2960.3 \pm 2400.0$ & $1284.7 \pm 992.3$ & $X n b$ & $X b>X n b$ & 1.74 & 0.064 & 8 \\
\hline Peace River (CFS) (winter-spring) & $433.3 \pm 152.4$ & $372.2 \pm$ & $X b=X n b$ & $X b<X n b$ & 0.63 & 0.267 & 20 \\
\hline Caloosahatchee river (CFS) (summer-fall) & $4966.3 \pm 2832.9$ & $3011.7 \pm$ & $X b=X n b$ & $X b>X n b$ & 1.57 & 0.073 & 10 \\
\hline Caloosahatchee river (CFS) (winter-spring) & $737.4 \pm 657.6$ & $1196.1 \pm 1212.6$ & $X b=X n b$ & $X b<X n b$ & 1.23 & 0.118 & 16 \\
\hline
\end{tabular}

Table 2: The seasonally split bloom and no bloom averages, the null and alternative hypothesis, the $\mathrm{T}$ value and the $\mathrm{P}$ value for each data set after the sequential analysis. 


\begin{tabular}{|c||c|c|}
\hline \multicolumn{3}{|c|}{ Loop Current Position } \\
\hline & Bloom & No Bloom \\
\hline LC N & 13 & 31 \\
LC S & 0 & 16 \\
\hline \hline
\end{tabular}

\begin{tabular}{|c||c|c|}
\hline \multicolumn{2}{|c|}{ Caloosahatchee River when LC N } \\
\hline & Bloom & No Bloom \\
\hline$>$ average & 7 & 13 \\
< average & 6 & 18 \\
\hline
\end{tabular}

\begin{tabular}{|c||c|c|}
\hline \hline \multicolumn{3}{|c|}{ Peace River when LC N } \\
\hline & Bloom & No Bloom \\
\hline$>$ average & 5 & 6 \\
$<$ average & 8 & 25 \\
\hline
\end{tabular}

Alongshore Wind Direction when LC N

\begin{tabular}{|c||c|c|}
\hline & Bloom & No Bloom \\
\hline upwelling & 10 & 20 \\
downwelling & 2 & 7 \\
\hline
\end{tabular}

Table 3: Matrix of bloom and no bloom counts for the Loop Current position, the Caloosahatchee River outflow when the LC is in the north, the Peace River outflow when the LC is in the north, and the alongshore wind direction when the LC is in the north. 

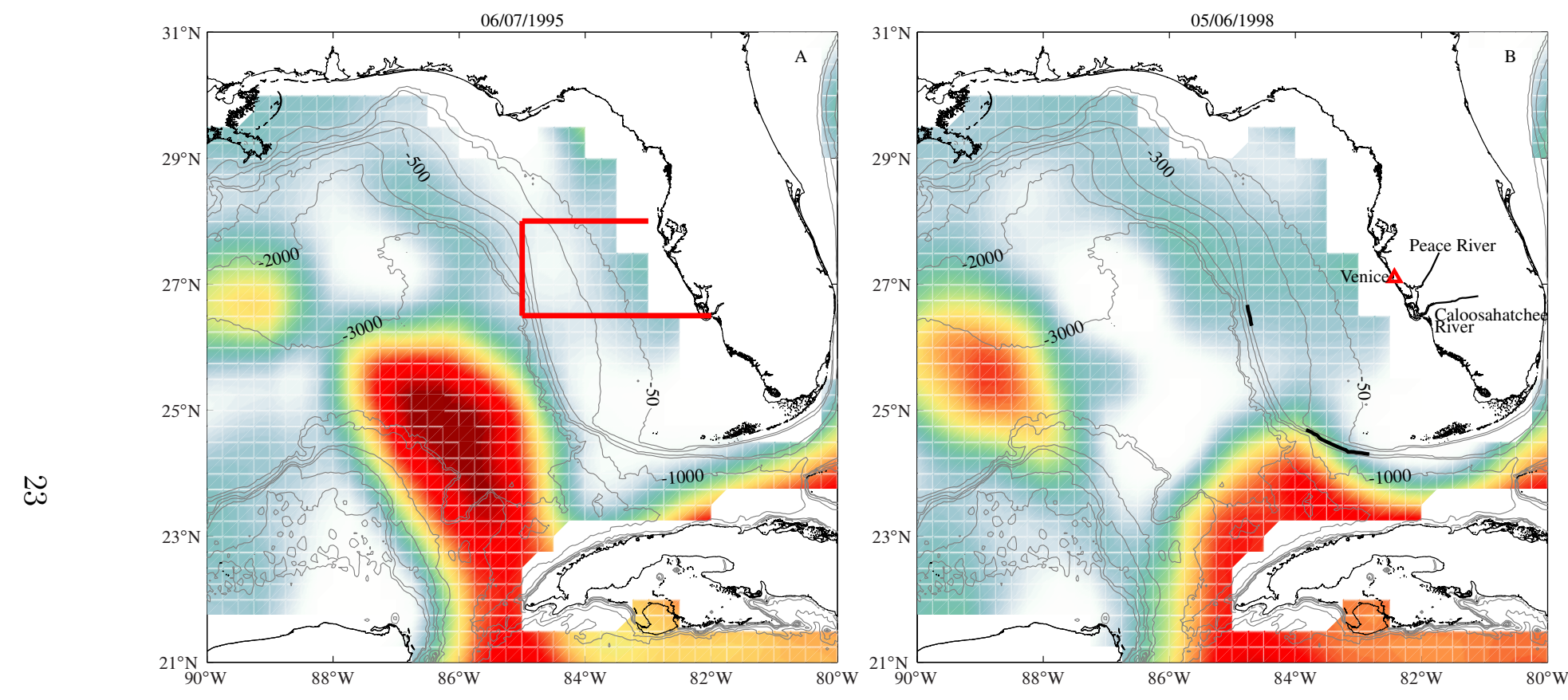

Figure 1: Progression of the Loop Current is shown by the background color of SSH where red indicates a higher SSH and white indicates a lower SSH. Panel (a) shows the LC in a northern position and (b) shows the LC in a southern position. The red box shows the area for which the K.brevis data were considered. Gray curves are the isobaths. The darker segments (in panel b) of the $300 \mathrm{~m}$ isobath correspond to the positions where the sea-surface height difference was taken. The Peace and Caloosahatchee rivers, and wind station are shown in panel (b). 

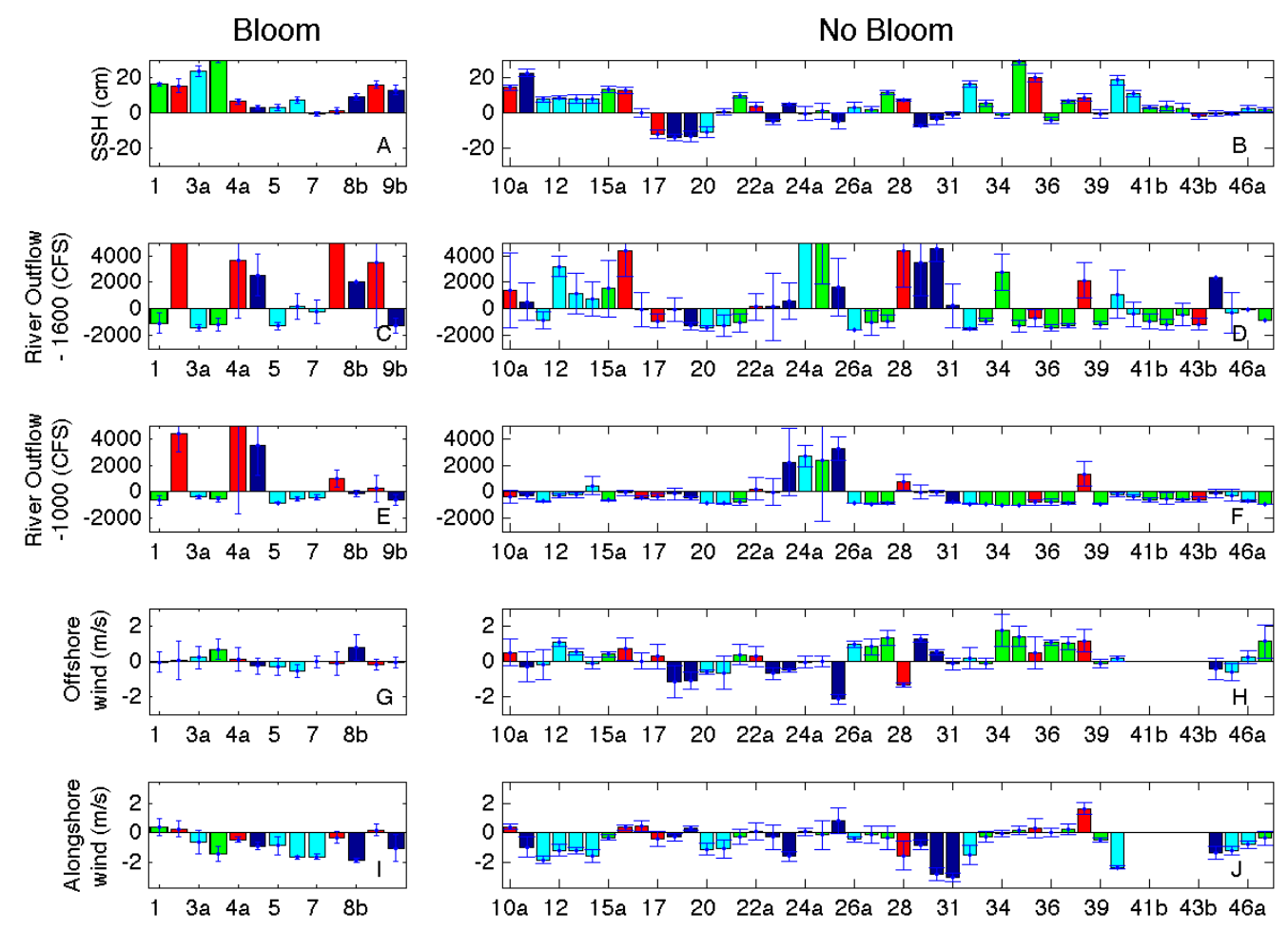

Figure 2: A series of bar charts with overlaying error bars for the various environmental variables considered here, for the bloom and no bloom periods detected. The $\mathrm{x}$ axis shows the bloom number, with continuous blooms that span seasons split into portions. The periods occurring in the fall months are shown in dark blue, winter in light blue, spring in green, and summer in red. Panels (a), (c), (e), (g) and (i) show the bloom data and panels (b), (d), (f), (h), and (j) show the no bloom data. For panels (a) and (b) bars above the line show a positive SSH difference and indicate the Loop Current is in the northern position while bars below the line show a negative SSH difference and indicate the LC is in the southern position. Panels (c) and (d) show the Caloosahatchee River outflow shifted by 1600 CFS, the mean river flow. Panels (e) and (f) show the Peace River outflow shifted by its average flow of 1000 CFS. Panels (g) and (h) show the cross-shore wind and panels (i) and(j) show the alongshore wind. 

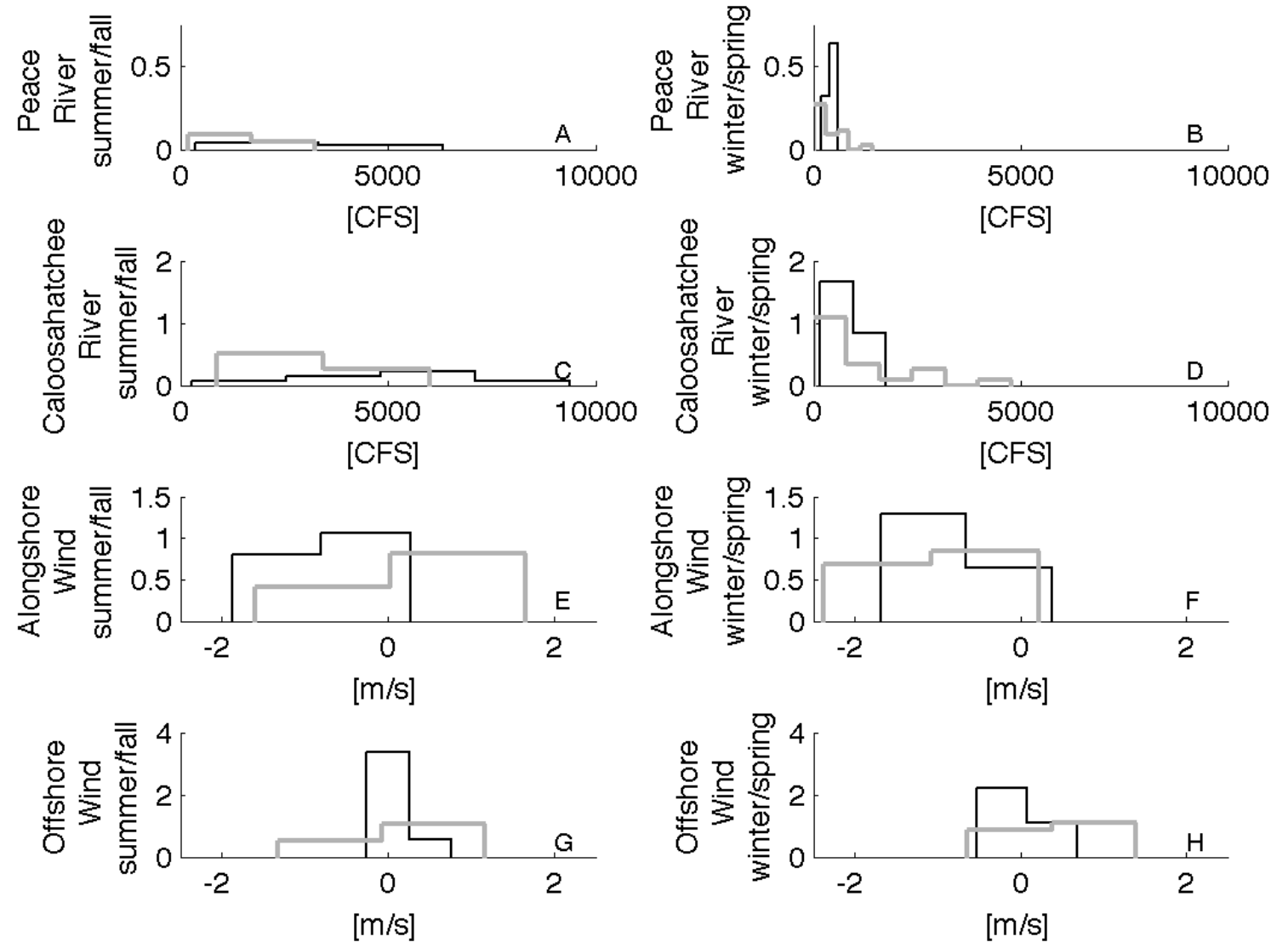

Figure 3: PDFs for the bloom (black) and no bloom (grey) periods detected of: (a) Peace River outflow during summer-fall (y-axis *100), (b) Peace River outflow during winter-spring (y-axis *100), (c) Caloosahatchee River outflow during summerfall(y-axis *1000), (d) Caloosahatchee River outflow during winter-spring(y-axis *1000), (e) Alongshore wind intensity during summer-fall, (f) Alongshore wind intensity during winter-spring, (g) Cross-shore wind intensity during summer-fall, and (h) Cross-shore wind intensity during winter-spring. 